\title{
The anti-A and anti-B antibody content of pooled plasma
}

\author{
J. DARNBOROUGH \\ From the National Blood Transfusion Service, Sheffield
}

SYNOPSIS Examination of a number of standard pools of plasma showed that a proportion contained 'immune' anti-A or anti-B antibodies. These may under certain conditions produce undesirable clinical and haematological side-effects.

Ottenberg's (1911) convenient concept of group O donors as universal donors, whose blood could be used for transfusing patients of any group, is no longer accepted without qualification. It is now generally recognized that the transfusion of group O blood to patients of group A and B, particularly the former, can be dangerous as haemolytic reactions can occur due to destruction of the recipients' cells by the anti-A (or B) in the donors' plasma. Aubert, Boorman, Dodd, and Loutit (1942) conclusively demonstrated that this was so, but ascribed the danger to the presence in the donors' plasma of high-titre saline anti-A (or B). Tisdall, Garland, Szanto, Hand, and Bonnett (1946) obtained similar results. The addition of group $A$ and $B$ substances to group $\mathrm{O}$ blood was investigated by several groups of workers and Tisdall, Garland, and Wiener (1946) were of the opinion that this was a safe method for preparing all group $O$ blood for use as universal donor blood. Witebsky (1948) described a new form of anti-A which he called 'immune anti-A' and Ervin and Young (1950) and Ervin, Christian, and Young (1950) showed 'that the type of antibody (i.e., natural or immune), as well as the titre, must be taken into account in any attempt to assess the dangers inherent in the use of universal donors, and that "conditioning" of group $O$ blood by addition of soluble $A$ and $B$ factors in conventional quantities may not effectively neutralize immune $\mathrm{A}_{1}$ and $B$ antibodies if such be present'. Although the presence of immune anti-A or anti-B antibodies is usually associated with a high-titre saline antibody, this is not always the case, and haemolytic reactions have been described in group A subjects transfused with group $\mathrm{O}$ blood with saline anti-A titres of 32 (Grove-Rasmussen, Shaw, and Marceau, 1953) and 16 (Stevens and Finch, 1954), associated in both cases

Received for publication 21 August 1962. with potent immune antibodies. It is now accepted that the transfusion of group $\mathrm{O}$ blood to $\mathrm{A}$ or $\mathrm{BC}$ recipients can be dangerous and that the danger? is associated with the presence of the immune typeo of anti-A or anti-B in the plasma of certain donors. Such donors have been termed 'dangerous universalo donors'.

Pooled plasma produced in this country is in the form of small pools of the supernatant plasma from nine or 10 blood donations so arranged that theyo include plasma from $\mathrm{O}, \mathrm{A}, \mathrm{B}$, and/or $\mathrm{AB}$ donors.0 This method of pooling produces to a variable degree 2 a mutual neutralization of the anti-A and $B$ content of the plasmas, the A substance in group A plasma3 reducing the anti-A antibody content and $B$ substance in group B plasma the anti-B content. Suchọ plasma is regarded as safe for universal use regard less of the recipients' $\mathrm{ABO}$ group. If the knowledge gained from the work on universal group $\mathrm{O}$ donors? is applied to pooled plasma, there is an obvious possibility that some of these pools too may contain? the dangerous immune anti-A or anti-B antibodies despite pooling and the consequent reduced saline antibody titres. Rutzky, Cohen, and Zuelzer (1956) described their clinical and haematological findings: in haemolytic anaemia caused by the transfusion of relatively large amounts of pooled plasma to group A children. The present paper reports observation $\$$ made in the light of present-day knowledge on pools of plasma prepared at the Regional Transfusione Centre, Sheffield. These were prepared mainly fronf whole blood more than 21 days old and sent to the Blood Products Laboratory, Lister Institute of Preventive Medicine, Elstree, for freeze drying.

It was arranged that when samples were taken fo sterility tests before freeze drying, an extra sample would be taken from Sheffield pools and returned to Sheffield for investigation. The pools chosen for 
investigation were the first 10 pools in each week's quota over a period of 11 weeks. Samples of the constituent plasmas in each pool were retained in Sheffield for further testing.

\section{TECHNIQUES}

Saline anti-A and anti-B titres were done on 103 plasma pools, 93 of which pools were also tested for the presence of immune anti-A and/or anti-B. In addition the saline and immune anti-A and anti-B titres, together with the content of the A and B substance, were measured in each of the constituent plasmas of 12 of the latter pools.

SALINE ANTIBODIES Titrations were done at room temperature using the classical technique of doubling dilutions of plasma against $A_{1}, B$, and pooled $O$ cells.

IMMUNE ANTIBODIES Witebsky's (1948) technique of partial neutralization was followed and tests for immune antibodies carried out in a selected pooled $A B$ serum medium, and also by the indirect anti-globulin method. Since immune antibodies, if present in the plasma pools, might be very weak, a careful partial neutralization technique was evolved. Commercial (Knickerbocker) A (porcine) and B (equine) blood group specific substances were used and, after preliminary experiments indicating the potency of these, the point of partial neutralization was estimated as follows.

Starting with a mixture of equal volumes of the standard solution of blood group substances and of the plasma under test, doubling dilutions of these were made using the same plasma as diluent. Thus concentrations of blood group substance in plasma ranging from 1 in 2 to 1 in 1,024 (10 tubes) were produced. After allowing to stand for one hour at bench temperature an equal volume of a 2 to $5 \%$ saline suspension of the appropriate $A_{1}$ or B cells was added to each tube, mixed and left for a further two hours. The last but one tube showing inhibition of agglutination was taken as the point of partial neutralization, and that concentration of blood group substance used for the immune anti-A or anti-B tests. $A_{1}$ cells and $B$ cells were used for detecting immune anti-A and immune anti-B respectively. In each case pooled $O$ cells were used as a control.

A AND B SUBSTANCES IN Plasma Serial dilutions of a standard anti-A or anti-B were made and to each dilution one volume of the plasma under test was added. To a second identical set of dilutions one volume of saline was added to each tube. After standing at bench temperature for one hour, one volume of a $2 \%$ saline suspension of $A_{2}$ or $B$ cells as appropriate was added to each tube. After a further two hours' incubation the tubes were examined microscopically for agglutination. The difference in titre between the saline control and the plasma-containing tubes is a rough indication of the amount of A or B substance in a given plasma and was expressed as an inhibition index (Aubert, Boorman, and Dodd, 1942), a reduction in titre of one tube being 2 , two tubes 4 , three tubes 8 , and so on.
RESULTS

SALINE ANTIBODIES All the pools had detectable anti-A and anti-B except for one sample in which no anti-A was detected. The anti-A titres varied from nil to 128 and anti-B titres from 1 to 32 (Table I).

TABLE I

SALINE TITRES OF ANTI-A AND ANTI-B IN 103 SAMPLES OF POOL PLASMA

\begin{tabular}{lllllllllll} 
Antibody & \multicolumn{1}{l}{ Titre } \\
\cline { 2 - 10 } & 0 & 1 & 2 & 4 & 8 & 16 & 32 & 64 & 128 & 256 \\
\hline Anti-A & 1 & 8 & 16 & 27 & 27 & 17 & 5 & 1 & 1 & 0 \\
Anti-B & 0 & 3 & 20 & 42 & 31 & 6 & 1 & 0 & 0 & 0
\end{tabular}

Thus the majority of saline titres were between 4 and 8 with very few over 16 . There were 18 different types of combination of constituent plasmas in the 91 pools of nine examined, and in the 12 pools of 10 , five different types. The four commonest pool combinations are shown in Table II.

TABLE II

FOUR COMMONEST PLASMA POOL COMBINATIONS Constituent Plasma No. of Pools

\begin{tabular}{ccccc}
\hline Group $A$ & Group B & Group $O$ & Group $A B$ & \\
\hline 3 & 1 & 5 & 0 & 20 \\
4 & 1 & 4 & 0 & 18 \\
3 & 1 & 4 & 1 & 11 \\
5 & 1 & 3 & 0 & 10
\end{tabular}

Examination of the saline antibody titres and the constitution of the pools shows, as might be expected, a general relationship between the final anti-A titre and the volumetric proportions of plasma containing anti-A to plasma containing $\mathbf{A}$ substance, and similarly with anti-B (Table III).

TABLE III

RELATION OF CONSTITUENTS OF POOLS TO SALINE ANTIBODY TITRE ${ }^{1}$

\begin{tabular}{lclc}
$\begin{array}{l}\text { Anti-A/A } \\
\text { Ratio }\end{array}$ & $\begin{array}{l}\text { Average } \\
\text { Anti-A Titre }\end{array}$ & $\begin{array}{l}\text { Anti-B/B } \\
\text { Ratio }\end{array}$ & $\begin{array}{l}\text { Average } \\
\text { Anti-B Titre }\end{array}$ \\
\hline $6 / 3(18$ pools) & $18 \cdot 5$ & $8 / 1(64$ pools $)$ & $6 \cdot 2$ \\
$5 / 4(39$ pools) & $12 \cdot 0$ & $7 / 2(20$ pools $)$ & $4 \cdot 7$ \\
$4 / 5(21$ pools) & $4 \cdot 3$ & $7 / 3$ and $6 / 3$ & $3 \cdot 4$ \\
& & $(7$ pools $)$ &
\end{tabular}

${ }^{1}$ Where

$\frac{\text { anti-A }}{\mathbf{A}}=\frac{\text { vol. plasma containing anti-A }}{\text { vol. plasma containing } \mathbf{A} \text { substance }}$

and

$\frac{\text { anti-B }}{\mathbf{B}}=\frac{\text { vol. plasma containing anti-B }}{\text { vol. plasma containing } B \text { substance }}$

IMMUNE ANTIBODIES Using the techniques described, 28 out of 93 pools were found to contain immune 
anti-A or immune anti-B antibodies or both (Table IV). The highest titre in $A B$ serum was $1 / 8$ and by the indirect anti-globulin method $1 / 16$.

\section{TABLE IV}

SUMMARY OF RESULTS ON TESTING

93 PLASMA POOLS FOR PRESENCE OF IMMUNE ANTI-A AND ANTI-B

\begin{tabular}{lccc} 
& $\begin{array}{l}\text { Immune } \\
\text { Anti-A } \\
\text { Only }\end{array}$ & $\begin{array}{l}\text { Immune } \\
\text { Anti-B } \\
\text { Only }\end{array}$ & $\begin{array}{l}\text { Immune } \\
\text { Anti-A } \\
\text { and } \\
\text { Anti-B }\end{array}$ \\
\hline $\begin{array}{l}\text { No. of pools found positive by } \\
\text { AB serum technique only }\end{array}$ & 17 & 4 & 1 \\
$\begin{array}{l}\text { No. of pools found positive by } \\
\text { antiglobulin and AB serum } \\
\text { techniques }\end{array}$ & 3 & 3 & 0 \\
$\begin{array}{l}\text { No. of pools found positive by } \\
\text { antiglobulin technique only }\end{array}$ & 0 & 0 & 0 \\
$\begin{array}{l}\text { Total } \\
\text { notal }\end{array}$ & 20 & 7 & 1
\end{tabular}

CONSTITUENTS OF THE POOLS The saline and immune anti-A and anti-B content and also the content of $A$ and $B$ substance were investigated in each constituent plasma of 12 selected pools. These 12 pools were selected as representatives of pools showing different types of antibody patterns, some with immune anti-A or anti-B and some without.

ANTIBODY PATTERNS Of the 12 pools fully investigated, four had immune anti-A or anti-B demonstrable in the final pool by the indirect anti-globulin test as well as the AB serum technique. Each of these four pools contained one or more constituent plasmas with strong immune antibodies demonstrable by both tests. Pool 1884 was particularly striking (Table V).

Where immune antibodies were not detectable in the final pool either none were present in the constituents, or if present they were comparatively weak and probably diluted out in the pools. Two pools showing some evidence of immune anti-A or anti-B in the final pool had none detectable in any of the constituents, a phenomenon analogous to that seen in pools of anti-D sera, examination of a final pool sometimes showing, in addition to anti-D, other antibodies which were not detectable in the separate components of the pool.

A AND B SUBSTANCE CONTENT The blood group substances detectable in the constituent plasmas showed variations of inhibition index from 0 to 4 in the case of group B plasma and 0 to 16 with the group A. Group A plasmas could be roughly subdivided into strong and weak inhibitors. A small series of tests on sera from known $A_{1}$ and $A_{2}$ donors confirmed the findings of Jakobowicz and Bryces (1941) that there was a relationship between the $A_{1}$ and $A_{2}$ sub-types and the amount of $A$ substanas in the serum or plasma, $A_{1}$ samples having more than $\mathbf{A}_{2}$ samples.

Table VI, showing the content of $A$ and $B$ sube stance of the constituents, is typical of the result obtained and may be studied in conjunction with Table V.

DRIED PLASMA That freeze-drying does not affect the presence of immune anti-A and anti-B in plasmfy was demonstrated by testing three bottles of plasmes which had been through the normal freeze-drying process at the Lister Institute. Two of these were pools known to have immune anti-A before drying $\overrightarrow{2}$ and the third, immune anti-B. In each case the immune antibody was demonstrable after recon? stitution with the normal volume of distilled water-

\section{DISCUSSION}

A proportion of pooled plasma prepared at this centre contains anti-A and anti-B of the so-callede immune type. In 93 pools six examples were found demonstrable by both the techniques used and further 22 by the $A B$ serum technique onlys (Table IV). Rutzky et al. (1956) investigated 15 commercially pooled plasmas from the U.S.A., 1 in of which gave a positive indirect anti-globulin testo with $A_{1}$ cells after partial neutralization and nine were similarly positive with $B$ cells. Only one of these, an anti-A, was regarded by the authors as significant. The saline antibody titres of the American pools were remarkably high, 10 of the 16 pools having anti-A titres of more than 64 and eigh? having anti-B titres of more than 32. No informatioris was given about the constitution of these pools? Despite quantitative differences, which may be due

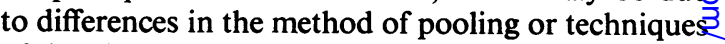
of titration, the American tests and the present much larger series both confirm that some plasma poolss contain immune anti-A and anti-B antibodies, i.e. 을 the same type of antibody as is present in the 'dangerous group $\mathrm{O}$ universal donor'. Rutzky et al? (1956) demonstrated without doubt that a haemolytico syndrome may follow large plasma transfusions Keitel and Wich (1954) also observed haemolysis ing infants of groups $A_{1}$ and $A_{1} B$ following poole $b$ plasma transfusions. Ebert and Emerson (1946) also were of the opinion that pooled plasma trans? fusions could cause at least some destruction of the recipients' cells if they were other than group $O$.

Pooled plasma is mainly used as an emergencs? transfusion fluid for treating hypovolaemic shock in such circumstances haemolysis of the patients' cells, which may only be shown by changes in the $\mathrm{Hb}$ 
TABLE V

\section{Poo}

Saline

After partial neutralization

Saline

AB serum

Indirect Coombs test

Constituents of Pool

Group B Saline V
After partial neutralization

Saline

AB serum

Indirect Coombs test -

Group O Saline C

After partial neutralization

Saline

AB serum

Indirect Coombs test -

Group 0 Saline $w^{1}$

After partial neutralization

Saline

AB serum

(t)

Indirect Coombs test

Group O Saline

After partial neutralization

Saline

AB serum

Indirect Coombs test

Group O Saline C

After partial neutralization

Saline

AB serum

Indirect Coombs test -

Group A Saline

After partial neutralization

Saline

AB serum

Indirect Coombs test

Group A Saline

After partial neutralization

Saline

AB serum

Indirect Coombs test

Group A Saline

After partial neutralization

Saline

AB serum

Indirect Coombs test

Group A Saline

After partial neutralization

Saline

AB serum

Indirect Coombs test

Partial haemolysis
POOL 1884 CONTAINING IMMUNE ANTI-A AND SHOWING IMMUNE ANTI-A IN TWO GROUP O CONSTITUENT PLASMAS

\begin{tabular}{lllllllll}
\hline 1 & 2 & 4 & 8 & 16 & 32 & 64 & 128 & 256
\end{tabular}

\begin{tabular}{lllllllll}
\hline 1 & 2 & 4 & 8 & 16 & 32 & 64 & 128 & 256
\end{tabular}

v $\quad$ v $++++\quad$ w

$\stackrel{\overrightarrow{\vec{C}}}{\ddot{C}}$ 
level, will almost certainly be missed or attributed to the primary condition of haemorrhage or burns. The observations of Rutzky et al. (1956) were made on haemophiliacs and those of Keitel and Wich (1954) on infants with gastroenteritis, both being groups of patients in whom side-effects are likely to be more easily observed than in, for example, surgical patients receiving plasma transfusions.

The paucity of reports in the literature on this aspect of the effects of pooled plasma transfusion support the belief that it is a reasonably safe transfusion fluid, but this may partly be due to lack of observations. The available evidence indicates that the transfusion of large volumes of pooled plasma should be avoided.

Support is lent to this view by the clinical observations of Topley, Bull, Maycock, Mourant, and Parkin (1962) who describe a haemolytic anaemia superimposed on other forms of red cell loss in some burned patients receiving more than three plasma volumes of reconstituted dried pooled plasma. These authors suggest that transfusion of up to 2 to 3 plasma volumes of such plasma does not cause excessive red cell loss in burned patients. It may well be that in such cases the patient's real need is for whole blood.

Cases of haemophilia or protein depletion treated by plasma transfusion should be given homologous ABO group plasma.

The treatment of $\mathrm{ABO}$ haemolytic disease of the newborn by transfusion calls for the use of group $O$ donors. In order to prevent the transfusion of undesirable anti-A or anti-B antibodies, it has been recommended that the donor cells be washed and then re-suspended in reconstituted pooled plasma or alternatively in plasma of the same group as the recipient (Dunsford and Bowley, 1955). Such resuspension in pooled plasma does not now seem desirable.

It is suggested that when there are any signs, such as an unexpectedly low $\mathrm{Hb}$, following pooled plasma transfusion which could be due to haemolysis, attention should be paid to the transfused plasma's anti-A and anti-B content.

Finally it seems appropriate to consider whether the present procedure of preparing plasma pools should be revised in such a way that donations with dangerously high antibody content are excluded.

I wish to thank Dr. W. d'A. Maycock and Dr. C. C. Bowley for their help in organizing this work. Thanks are also due to Mrs. Una Read for her help in preparing the several hundred plasma samples needed.

\section{REFERENCES}

Aubert, E. F., Boorman, K. E., and Dodd, B. E. (1942). J. Path. Bact. $54,89$.

$\longrightarrow,-,-$ and Loutit, J. F. (1942). Brit. med. J., 1, 659.

Dunsford, I., and Bowley, C. C. (1955). Techniques in Blood Grouping. Oliver and Boyd, Edinburgh.

Ebert, R. V., and Emerson, C. P. (1946). J. clin. Invest., 25, 627.

Ervin, D. M., Christian, R. M., and Young, L. E. (1950). Blood, 5, 553.

$\longrightarrow$, and Young, L. E. (1950). Ibid., 5, 61.

Grove-Rasmussen, M., Shaw, R. S., and Marceau, E. (1953). Amer. J. clin. Path., 23, 828.

Jakobowicz, R., and Bryce, L. M. (1941). Med. J. Aust., 1, 318.

Keitel, H. G., and Wich, J. (1954). Amer. J. Dis. Child., 87, 537.

Ottenberg, R. (1911). J. exp. Med., 13, 425.

Rutzky, J., Cohen, F., and Zuelzer, W. W. (1956). Blood, 11, 403.

Stevens, A. R. Jr., and Finch, C. A. (1954). Amer. J. clin. Path., 24, 612 .

Tisdall, L. H., Garland, D. M., Szanto, P. B., Hand, A. M., and Bonnett, J. C. (1946). Ibid., 16, 193.

,-- , and Wiener, A. S. (1946). J. Lab. clin. Med., 31, 437.

Topley, E., Bull, J. P., Maycock, W. d'A., Mourant, A. E., and Parkin, D. (1962). J. clin. Path., 16, 79.

Witebsky, E. (1948). In The Rh Factor, ed. J. M. Hill and W. Dameshek, p. 66. Blood, Special Issue, No. 2. 